\title{
Effects of drying eggs and egg storage on hatchability and development of Anopheles arabiensis
}

\author{
Inamullah Khan ${ }^{1 *}$, David Damiens², Sharon M Soliban ${ }^{2}$ and Jeremie RL Gilles²
}

\begin{abstract}
Background: The mass rearing of insects requires a large colony from which individuals can be harvested for sterilization and release. Attention is given to larval food requirements and to handling and rearing conditions to ensure predictability and synchrony of development. Maximizing production requires optimized adult holding to ensure mating success, blood feeding and oviposition. Appropriate egg storage and harvesting is necessary to compensate any unpredicted reduction in egg production.

Methods: Anopheles arabiensis eggs were collected on wet filter paper in eggs cups. The eggs were cleaned and then dried over a suction device with adjustable speed and time. The effects of drying, storage time and storage condition (wet, dry and bulk with relative humidity $75 \pm 5 \%$ and storage temperatures of 10,15 and $20^{\circ} \mathrm{C}$ ) on hatch rate, duration of larval stages (L1 to pupal stage), duration of L1 to adult emergence, survival of L1 to pupal stage and the survival of $L 1$ to adult emergence were investigated. Post drying and post storage hatch rates were determined by counting hatched and unhatched eggs and were confirmed by counting the viable larvae in the rearing medium.
\end{abstract}

Results: The hatch rate of eggs dried at wind speeds of 1.0 or $1.8 \mathrm{~m} / \mathrm{s}$ was not significantly different from the control, but eggs dried at $3.0 \mathrm{~m} / \mathrm{s}$ resulted in very low (64\%) hatchability as compared to the control (82\%). Eggs stored at $20^{\circ} \mathrm{C}$ and $75 \pm 5 \% \mathrm{RH}$ in bulk in an aerated vial showed better survival than eggs stored in wet or dry conditions at 10 or $15^{\circ} \mathrm{C}$. No significant changes in larval duration and survival were recorded after six days of bulk storage.

Conclusion: Anopheles arabiensis eggs can be stored in bulk at $20^{\circ} \mathrm{C}$ and $75 \pm 5 \% \mathrm{RH}$ for six days without any decrease in hatch rate, and up to 9 days with no impact on larval development.

Keywords: Sterile insect technique, Anopheles, Mass rearing, Egg management, Volumetric estimation

\section{Background}

The sterile insect technique (SIT) is a species-specific and environmentally friendly method of insect pest control based on the release of large numbers of sterile insects [1]. Mass-reared (male) insects exposed to ionizing radiation prior to release transfer their sterile sperm to wild females during mating, causing a reduction in the fertility of the female target population resulting in a progressive decline of the pest population. The efficacy of the SIT relies on maintaining a continuously high ratio of sterile to fertile males within the target area and the competitiveness of

\footnotetext{
* Correspondence: inamullah17@gmail.com

${ }^{1}$ Nuclear Institute for Food and Agriculture, G.T. Road, Peshawar, Pakistan Full list of author information is available at the end of the article
}

these sterile males. For example, from 1977 to 1979 on the Pacific coast of El Salvador, 0.5 to 1.25 million sterile male pupae were released daily during the SIT programme against Anopheles albimanus [2,3].

The Tropical Medicine Research Institute in Sudan, with the support of the Food and Agriculture Organization of the United Nations (FAO) and the International Atomic Energy Agency (IAEA) has initiated a study to assess the feasibility of integrating the SIT for the area wide control of the important malaria vector Anopheles arabiensis along the Nile River in Northern State, Sudan. To control An. arabiensis in Sudan, the production of one million An. arabiensis sterile males per day is anticipated [4]. To achieve this goal and obtain a sustainable and affordable

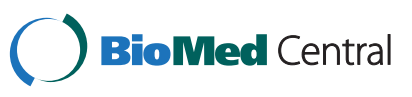


production, the Insect Pest Control Laboratory (IPCL) of the Joint FAO/IAEA Division of Nuclear Techniques in Food and Agriculture has been supporting this project with the development of low cost diets [5,6], massrearing equipment and optimized rearing protocols [7]. A larval rearing unit composed of a rack containing 50 trays, a larvae-pupae separator [8] and an adult massrearing cage [9] have been developed and evaluated for An. arabiensis and are now being transferred to field projects for further validation under operational conditions.

A crucial aspect in the rearing of mosquitoes, such as An. arabiensis, is the management of the large quantity of eggs produced in the mass-rearing cage. Handling and measuring high volumes of fresh eggs is tedious and impractical, primarily due to the sticky properties of fresh eggs. Moreover, Anopheles eggs remain viable for a short time only on wet substrates [10] and efforts must be directed towards determining the drying and storing conditions for Anopheles eggs that would be least detrimental to development parameters. Therefore, methods of drying eggs have been developed to allow manipulation and measurement in the context of the SIT, for instance for An. albimanus, Anopheles quadrimaculatus and Anopheles stephensi [11-14]. Eggs of An. albimanus and An. quadrimaculatus can survive the drying process and withstand considerable periods of storage [15]. After drying, eggs could be easily manipulated and the number of eggs estimated volumetrically. Moreover, due to the high number of eggs and adults that must be produced per day, storage of eggs could help manage insect production objectives.

The present study was conducted to determine the effects of drying, storage temperature, storage conditions (dry, wet, bulk) and storage time on the hatchability of An. arabiensis eggs and the post-hatch life parameters including larval duration and survival to adult emergence.

\section{Methods}

\section{Egg collection and cleaning}

The larval stages of $A n$. arabiensis Dongola strain were reared in 1 litre deionized water held in plastic trays $(30 \times 40 \times 8 \mathrm{~cm})$. Larvae were fed a diet of ground fish food (Koi Floating Blend ${ }^{\circledR}$, Aquaricare ${ }^{\circledR}$, New York, USA). Pupae were separated and put into metal-framed cages (each $60 \times 60 \times 60 \mathrm{~cm})\left(\right.$ BugDorm $\left.^{\circledR}\right)$. Adults had constant access to $10 \%$ sucrose plus $0.2 \%$ methylparaben solution [5]. The rearing conditions were $27 \pm 1^{\circ} \mathrm{C}$ and $60 \pm 10 \%$ RH with a 12:12 LD photoperiod including dusk $(1 \mathrm{~h})$ and dawn $(1 \mathrm{~h})$. Each cage contained approximately 2000-3000 adults. For egg production females were given a blood meal (mechanically defibrinated bovine blood). Gravid females oviposited in plastic cups with black lining on the sides and a wet sponge on the bottom over which a filter paper disc was placed.
Eggs were collected and then cleaned with an apparatus (Figure 1) constructed from transparent Plexiglas pipes cut into two pieces, 9 and $12 \mathrm{~cm}$ long. Two plastic funnels (each $12 \mathrm{~cm}$ diameter) were used. A polyester 500-micron mesh was glued with silicon to the centre of one funnel. The second funnel was cut in the middle leaving a hole $(6 \mathrm{~cm}$ diameter $)$ at the bottom. Another polyester cloth (that retained eggs) was glued over the cut end of the second funnel. Both funnels were fitted over each other with the help of a ring. Eggs collected on the blotting paper in the egg cups were washed into the upper funnel with the help of a wash bottle. Excess debris and insect particles were collected in the top funnel but eggs could pass through it and were collected on the second mesh. Eggs were then washed for $1 \mathrm{~min}$ with a gentle flow of deionized water.

\section{Effect of egg drying on hatch rate}

The lower portion of the apparatus with the funnel and clean eggs was detached and placed over a suction device with adjustable speed (Figure 2). The wind speed and drying duration were adjusted so that all eggs dried and no clumping was apparent. Three wind speeds (1.0, 1.8 and $3.0 \mathrm{~m} / \mathrm{s}$ ) and four drying durations $(10,15,20$ and $25 \mathrm{~min}$ ) were tested. Wind velocity was measured using a Testo 417 anemometer (Testo Ltd, Alton, UK). For each combination of wind speed and drying duration, three replicates of 200 eggs were used. At the end of each treatment, eggs were placed in cups lined on the inside with $2.5-\mathrm{cm}$-wide filter paper strips and containing $40 \mathrm{ml}$ deionized water (providing $1 \mathrm{~cm}$ water at the bottoms of the cups). The tops of the cups were covered by placing a tray over them to reduce evaporation. Control eggs were taken directly from the filter paper in egg cups and divided into three replicates of 200 eggs as described

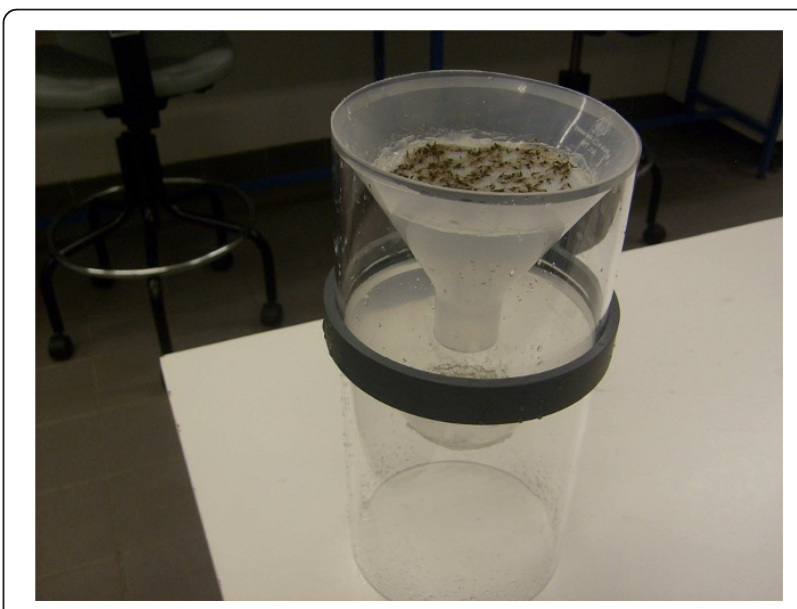

Figure 1 Apparatus for cleaning and drying eggs. Detachable funnels and rings holding the funnels above each other. 


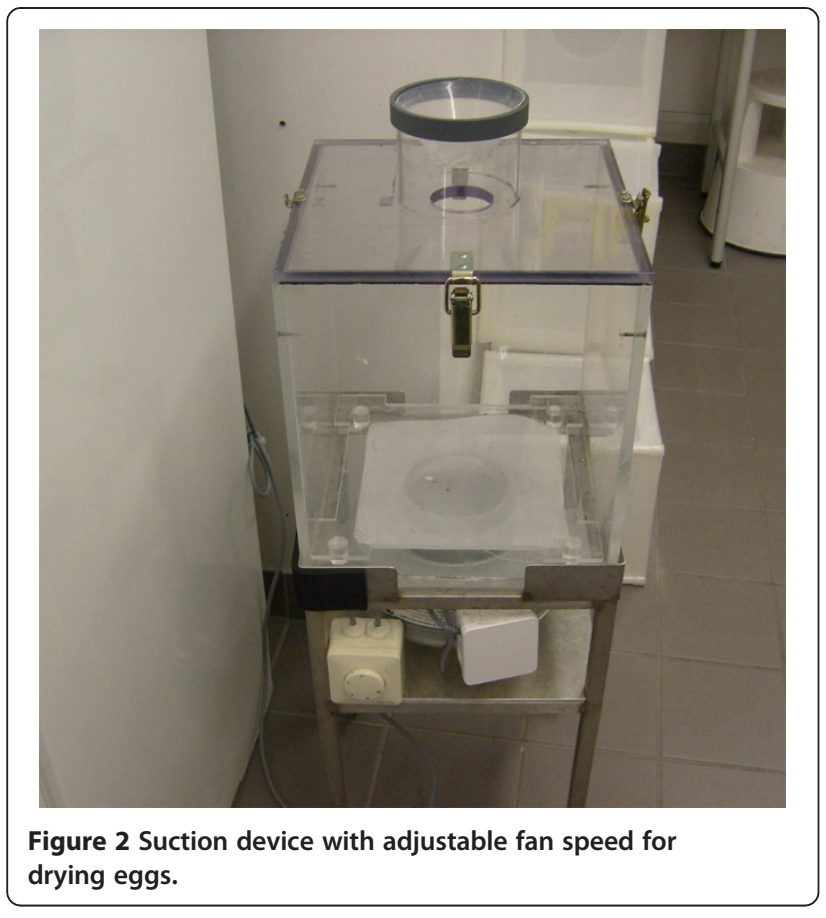

above. All cups were placed in a temperature-controlled rearing room at $27^{\circ} \mathrm{C}$ for hatching.

Eggs sticking to the sides of the filter paper after $24 \mathrm{~h}$ were rinsed down into the water. Filter papers lining the sides of the hatching cups were removed with forceps after $48 \mathrm{~h}$ and dried on tissue paper. Hatched and unhatched eggs sticking to the sides of the filter papers were counted with a stereomicroscope. The hatch rate was confirmed by counting the number of viable larvae in each cup.

\section{Effects of egg storage on hatch rate}

Based on the results of the experiment on wind speed (see results section), all eggs were dried at $1.8 \mathrm{~m} / \mathrm{s}$ for $20 \mathrm{~min}$. The following experiment was conducted to determine the most suitable temperature $\left(10,15\right.$ or $\left.20^{\circ} \mathrm{C}\right)$, duration (1 to 8 days) and condition (dry, wet or bulk) for extended periods of storage. In the dry condition, eggs were stored in $200 \mu \mathrm{l}$ Eppendorf tubes with caps closed; in the wet condition, eggs were stored in $200 \mu \mathrm{l}$ Eppendorf tubes with wet cotton at the top end. For both of the conditions, 90 tubes with 200 eggs each were prepared, with 30 tubes being stored at each of the three temperatures. Relative humidity was held at $75 \% \pm 5$ in storage facilities.

The hatch rates of eggs stored in either wet or dry conditions were determined daily by withdrawing three tubes from each storage temperature and dropping eggs in cups containing $40 \mathrm{ml}$ deionized water. In the bulk method about 10,000 dry eggs were stored in $1.5 \mathrm{ml}$ graduated glass bottles with screw caps modified for air circulation with a 2-mm hole at the upper end. Each bottle with eggs was then stored at 10 or $15^{\circ} \mathrm{C}$ in an incubator or at $20 \pm 2^{\circ} \mathrm{C}$ in a temperature-controlled room $(75 \pm 5 \% \mathrm{RH})$. The hatch rate of eggs stored in bulk was determined daily from approximately 600 eggs that were replicated in three hatching cups each with about 200 eggs. All cups with water and eggs were then placed in a clean tray and covered with another tray to prevent contamination and water evaporation. The tray with the cups was placed in a temperature-controlled rearing room at $27 \pm 1^{\circ} \mathrm{C}, 60 \pm 10 \% \mathrm{RH}$ and a 12:12 LD photoperiod including dusk $(1 \mathrm{~h})$ and dawn $(1 \mathrm{~h})$. The status of egg hatch was observed with a stereomicroscope after $48 \mathrm{~h}$ by checking hatched and unhatched eggs and the number of larvae in the medium.

\section{Effects of egg storage duration on larval development parameters}

Eggs dried at $1.8 \mathrm{~m} / \mathrm{s}$ for $20 \mathrm{~min}$ were stored at $20 \pm 2^{\circ} \mathrm{C}$ and $75 \pm 5 \% \mathrm{RH}$ in bulk as described above. The effects of storage duration on hatch rate, duration of larval stages (L1 to pupal stage), duration of L1 to adult emergence, survival of L1 to pupal stage and survival of L1 to adult emergence were observed. The hatch rate was determined by counting eggs on paper and counting L1 from three cups of 200 eggs as described above. For assessment of larval developmental parameters, $150 \mu \mathrm{l}$ of $1 \%(\mathrm{w} / \mathrm{v})$ fish food (Koi Floating Blend ${ }^{\circledR}$ ) were added to the water in hatching cups as food for hatching larvae. To test the effects of storage duration on duration of larval stages (L1 to pupal stage), duration of L1 to adult emergence, survival of L1 to pupal stage and survival of L1 to the adult emergence, one subsample of $32 \mathrm{~L} 1 \mathrm{~s}$ from each replicate cup were transferred into standard 90-mm-diameter disposable polystyrene Petri dishes with $32 \mathrm{ml}$ of deionized water. Larvae in each dish were fed with $640 \mu \mathrm{l}$ of $1 \%(\mathrm{w} / \mathrm{v})$ Koi fish food on a daily basis until pupation. Larval mortality was noted (based on dead larvae in the dishes). Once pupae had formed they were picked up with a plastic pipette and transferred to plastic tubes containing about $2 \mathrm{ml}$ water until adult emergence.

\section{Volumetric estimation of the number of dried eggs}

Dry eggs were poured into a $1.5 \mathrm{ml}$ screw-capped graduated glass bottle, the cap of which was modified into a tube shape with a $2-\mathrm{mm}$ hole at the top to permit the transfer of eggs into another tube. Eppendorf tubes were marked at different volumes: 10, 20, 30, 40 50,100 and $150 \mu \mathrm{l}$ using automatic pipettes for the measurement, each replicated three times. For each volume, these tubes were filled to the mark with dried An. arabiensis eggs from the graduated glass bottles. All tubes were centrifuged for 2-3 sec so that the eggs reached the measured 
level. Once the tube was filled, the eggs were poured onto a gridded paper at the bottom of a Petri dish. Eggs were spread over the gridded area with a camel hair brush and counted with a stereomicroscope. The procedure was repeated three times resulting in three egg quantity estimations for each volume. Correlation between the number of eggs and volume was done using Pearson correlation software.

\section{Statistical analysis}

Data on egg drying time and wind speed were analyzed using the two-way ANOVA followed by Tukey's HSD test. To study the effect of storage period, temperature and storage condition on hatching rate, correlation between percent hatch and storage period for each temperature/ storage condition were tested and compared. Pearson correlation coefficient were calculated and tested for each relationship. Least-Squares regression lines were then determined and slopes and intercepts of lines were tested with Analysis of variance in General Linear Model [16] using storage period as covariate. If the null hypothesis for 'treatment temperature/storage condition' was rejected (i.e. if its p-value is less than alpha), the intercepts of the regression models were not all equal. If the null hypothesis for 'storage period "treatment temperature/storage condition' was rejected, then the slopes of the regression models were not all equal. Pearson correlation coefficient calculation and tests of slopes and intercepts were performed using Minitab release 16 (Minitab, State College, PA). The effects of bulk storage at $20^{\circ} \mathrm{C}$ on hatch rate, duration of larval stages (L1 to pupal stage), duration of L1 to adult emergence, survival of L1 to pupal stage and survival of L1 to adult emergence were analyzed using ANOVA, with a completely randomized design, followed by Tukey's HSD test. Pearson's correlation coefficient between volume and the number of eggs were determined. Simple linear regression was performed between the number of eggs and volume. All statistical analyses were done using Statistix 8.1 (Analytical Software, Tallahassee, FL).

\section{Results}

\section{Effect of egg drying on hatch rate}

Effects of drying time and wind speed on percent hatch $( \pm \mathrm{SD})$ of An. arabiensis eggs have been summarized in Table 1 . Two way ANOVA shows extremely significant effect of both drying duration $(\mathrm{F}=12.4, \mathrm{DF}=3, \mathrm{P}<0.001)$ and wind speed $(\mathrm{F}=79.9, \mathrm{DF}=3, \mathrm{P}<0,001)$ on the egg hatch rate. High significant interaction between drying duration and wind speed has been also observed $(F=8.4$, $\mathrm{DF}=9, \mathrm{P}<0.001)$. The significant interaction means that the effect of one variable is significantly different for each levels of the other variable. Tukey post-tests indicate that there is no significant differences in hatch rate between 10, 15, 20 min drying duration. The drying duration of
Table 1 Effects of drying time and wind speed on percent hatch of An. arabiensis eggs

\begin{tabular}{lcccc}
\hline Wind speed $(\mathbf{m} / \mathbf{s})$ & \multicolumn{4}{c}{ Drying time ( $\mathbf{m i n})$} \\
\hline & $\mathbf{1 0}$ & $\mathbf{1 5}$ & $\mathbf{2 0}$ & $\mathbf{2 5}$ \\
1.0 & $83.3 \pm 4.3$ & $81.0 \pm 5.6$ & $80.0 \pm 2.8$ & $81.9 \pm 4.5$ \\
1.8 & $79.9 \pm 6.1$ & $81.4 \pm 5.9$ & $\mathbf{8 1 . 8 6} \pm \mathbf{0 . 9}$ & $\mathbf{7 5 . 4 4} \pm \mathbf{4 . 5}$ \\
3.0 & $67.5 \pm 1.6$ & $\mathbf{6 6 . 3} \pm \mathbf{2 . 6}$ & $\mathbf{6 4 . 2} \pm \mathbf{3 . 0}$ & $\mathbf{3 5 . 8} \pm \mathbf{8 . 0}$ \\
Control & $81.7 \pm 2.5$ & $81.7 \pm 2.5$ & $81.7 \pm 2.5$ & $81.70 \pm 2.5$
\end{tabular}

The bold indicates that the eggs were totally dried following treatments. Totally dried mean, eggs were dry and not clumping with each other.

25 minutes shows a significant difference with all the other times. No significant difference has been observed between controls, 1.0 , and $1.8 \mathrm{~m} / \mathrm{s}$ wind speed treatment groups, but the $3.0 \mathrm{~m} / \mathrm{s}$ treatment group was significantly different from the others. Thus the only treatment where all eggs were dried at the end and that showed no significant effect of the drying duration and wind speed was a speed of $1.8 \mathrm{~m} / \mathrm{s}$ for $20 \mathrm{~min}$. This combination of wind speed and duration was used in the remaining experiments.

\section{Effects of egg storage on hatchability}

Effects of storage period, storage condition and temperature on per cent hatch $( \pm \mathrm{SD})$ of An. arabiensis eggs have been summarized in Table 2 . To study the effect of the different treatments on hatching rate, relationship between percent hatch and storage period for each treatment temperature/storage condition have been compared (Figure 3). Pearson correlation coefficient has been calculated for each relationship and was significant for each temperature/storage condition except for wet $15^{\circ} \mathrm{C}$ (it has been so discarded from all future regression line parameters comparison). Slopes and intercepts were tested with Analysis of variance in General Linear Model using storage period as covariate. The intercepts of the regression models are not significantly different $(F=0.75, D F=7$, $\mathrm{P}=0.63)$ while slopes are significantly different $(\mathrm{F}=14.67$, $\mathrm{DF}=7, \mathrm{P}<0.001$ ). According to the Figure 3, the regression line of Bulk $20^{\circ} \mathrm{C}$ and Wet $20^{\circ} \mathrm{C}$ show the lower slope among all the regression lines (1.0 and 1.3 respectively) that also are not significantly different.

Based on these results, egg storage in bulk at $20^{\circ} \mathrm{C}$ was chosen as the appropriate environment for additional investigations on the effects of storage temperature and condition on life parameters such as larval development and adult emergence.

\section{Effects of egg storage duration on larval development parameters}

Table 3 summarizes the results on the effects of egg storage duration in bulk condition at $20^{\circ} \mathrm{C}$ on larval developmental parameters. The developmental period from 
Table 2 Effect of storage period, storage condition and temperature on percent hatch ( \pm SD) of An. arabiensis eggs

\begin{tabular}{|c|c|c|c|c|c|c|c|c|c|}
\hline \multirow{3}{*}{$\begin{array}{l}\text { Storage } \\
\text { period (d) }\end{array}$} & \multicolumn{9}{|c|}{ Storage condition and temperature $\left({ }^{\circ} \mathrm{C}\right)$} \\
\hline & \multicolumn{3}{|c|}{ Bulk } & \multicolumn{3}{|c|}{ Dry } & \multicolumn{3}{|c|}{ Wet } \\
\hline & 10 & 15 & 20 & 10 & 15 & 20 & 10 & 15 & 20 \\
\hline 1 & $78.6 \pm 3.6$ & $82.9 \pm 1.2$ & $83.3 \pm 3.0$ & $86.5 \pm 1.9$ & $87.0 \pm 3.4$ & $86.0 \pm 2.8$ & $82.1 \pm 3.0$ & $79.1 \pm 0.3$ & $81.6 \pm 1.2$ \\
\hline 2 & $80.5 \pm 2.6$ & $78.0 \pm 3.8$ & $80.3 \pm 2.6$ & $81.6 \pm 3.6$ & $73.1 \pm 4.8$ & $75.9 \pm 3.8$ & $82.4 \pm 2.8$ & $76.7 \pm 3.9$ & $81.3 \pm 0.9$ \\
\hline 3 & $56.0 \pm 4.6$ & $61.2 \pm 7.0$ & $78.6 \pm 3.5$ & $53.2 \pm 7.7$ & $52.6 \pm 3.0$ & $42.5 \pm 8.0$ & $56.6 \pm 2.6$ & $46.6 \pm 10.2$ & $69.1 \pm 2.5$ \\
\hline 4 & $60.1 \pm 4.7$ & $56.2 \pm 2.5$ & $76.7 \pm 2.8$ & $49.9 \pm 3.9$ & $44.6 \pm 5.1$ & $39.8 \pm 1.6$ & $26.3 \pm 3.5$ & $60.6 \pm 1.1$ & $73.8 \pm 3.9$ \\
\hline 8 & $33.1 \pm 2.5$ & $28.6 \pm 4.4$ & $75.6 \pm 3.5$ & $27.3 \pm 2.5$ & $22.3 \pm 8.2$ & $12.4 \pm 1.2$ & $25.3 \pm 1.9$ & $59.2 \pm 0.8$ & $72.1 \pm 4.3$ \\
\hline
\end{tabular}

L1 to pupa and L1 to the adult stage did not differ significantly from the control. Surprisingly a shorter developmental time was observed for eggs stored at a longer duration. Percent survival from the L1 to the pupal stage was the same for up to 8 days of storage. Similar results were observed for survival up to the adult stage. The percent hatch for eggs up to 6 days of storage was about $77 \%$, and not significantly different from the control. However, the hatch rate declined starting at 7 days of storage. In summary, no differences in larval development and the survival rate to adult emergence were observed when stored 1 to 8 days, and a significant decline in egg hatch was observed after 6 days of storage.

\section{Volumetric estimation of dried eggs}

Based on eggs counted from volumes between 10 and $150 \mu \mathrm{l}$, egg number and volume followed a linear relationship $(\mathrm{y}=107.45+81.14 \mathrm{x}, r=0.99$ with $P=0.0001$ and $R^{2}=0.986$ ) (Figure 4). A total of 937, 1716, 2617, 3466 and 4370 eggs were counted from 10, 20, 30, 40 and $50 \mu \mathrm{l}$, respectively. The mean number of eggs in $150 \mu \mathrm{l}$ was 12,734 . There was a positive and significant correlation between the number of eggs and volume. The linear relationship was also examined using a simple linear regression equation. For each unit change in volume the number of eggs increased by 81 . The goodness of fit test shows a very high value of $R^{2}\left(R^{2}=0.98\right)$, meaning

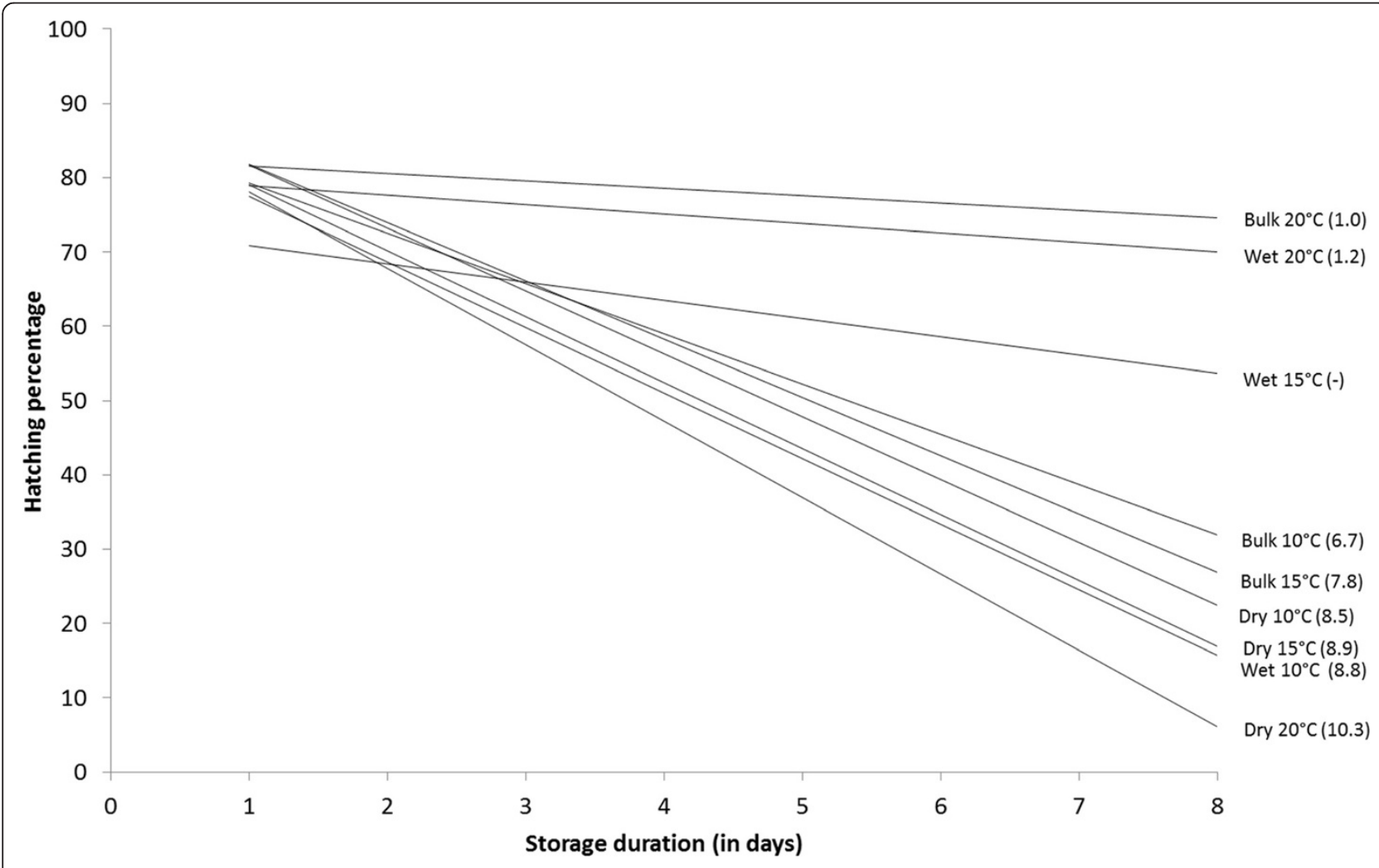

Figure 3 Relationship between percent hatch and storage duration for each treatment temperature/storage condition. Slope of each regression line is indicated in parentheses (no slope was given for Wet $15^{\circ} \mathrm{C}$ since the Pearson correlation coefficient was not significant). 
Table 3 Effects of bulk storage on hatchability, larval duration, emergence and survival of An. arabiensis when eggs were stored at $20^{\circ} \mathrm{C}$

\begin{tabular}{|c|c|c|c|c|c|c|c|c|c|c|}
\hline \multirow{2}{*}{$\begin{array}{l}\text { Egg storage period (d) } \\
1\end{array}$} & \multicolumn{2}{|c|}{$\begin{array}{l}\text { Percentage } \\
\text { hatching }\end{array}$} & \multicolumn{2}{|c|}{$\begin{array}{l}\text { Duration larval } \\
\text { stages (d) }\end{array}$} & \multicolumn{2}{|c|}{$\begin{array}{l}\text { Duration L1 to adult } \\
\text { emergence (d) }\end{array}$} & \multicolumn{2}{|c|}{$\begin{array}{l}\text { Survival L1 to pupal } \\
\text { stage (\%) }\end{array}$} & \multicolumn{2}{|c|}{$\begin{array}{l}\text { Survival L1 to adult } \\
\text { emergence (\%) }\end{array}$} \\
\hline & $75.1 \pm 2.3$ & $b$ & $10.2 \pm 0.3$ & $a$ & $11.2 \pm 0.3$ & $a$ & $95.3 \pm 0.6$ & $a$ & $93.7 \pm 0.8$ & $a$ \\
\hline 2 & $82.8 \pm 2.8$ & a & $9.2 \pm 0.3$ & $b c$ & $10.8 \pm 0.2$ & $a$ & $94.5 \pm 0.9$ & $a b$ & $93.0 \pm 0.9$ & $a b$ \\
\hline 3 & $78 . \pm 1.5$ & $a b$ & $9.8 \pm 0.1$ & a & $10.7 \pm 0.2$ & $a b$ & $93.7 \pm 0.0$ & $a b$ & $91.4 \pm 0.9$ & $a b$ \\
\hline 4 & $78 . \pm 2.4$ & $a b$ & $9.8 \pm 0.4$ & a & $10.8 \pm 0.4$ & $a b$ & $93.0 \pm 0.9$ & $a b c$ & $91.4 \pm 0.9$ & $a b$ \\
\hline 5 & $79.9 \pm 4.5$ & $a b$ & $9.3 \pm 0.1$ & $b$ & $10.3 \pm 0.1$ & $b c$ & $93.7 \pm 0.8$ & $a b$ & $91.4 \pm 0.9$ & $a b$ \\
\hline 6 & $76.8 \pm 4.5$ & $a b$ & $8.2 \pm 0.2$ & $b c$ & $10.2 \pm 0.2$ & $\mathrm{~cd}$ & $92.2 \pm 0.6$ & bc & $89.8 \pm 1.0$ & $a b$ \\
\hline 7 & $68.9 \pm 4.6$ & c & $9.1 \pm 0.2$ & $b c$ & $10.2 \pm 0.2$ & $\mathrm{~cd}$ & $93.0 \pm 0.9$ & $a b c$ & $89.8 \pm 1.0$ & $a b$ \\
\hline 8 & $68.9 \pm 4.6$ & c & $9.1 \pm 0.0$ & $b c$ & $10.1 \pm 0.0$ & $\mathrm{~cd}$ & $93.0 \pm 0.5$ & $a b c$ & $89.8 \pm 0.96$ & $a b$ \\
\hline 9 & $53.2 \pm 6.0$ & $d$ & $8.8 \pm 0.1$ & c & $9.8 \pm 0.2$ & $d$ & $90.6 \pm 0.0$ & c & $89.1 \pm 0.6$ & $b$ \\
\hline 11 & $22.6 \pm 6.2$ & e & -— & & - & & -- & & -— & \\
\hline Control & $78.5 \pm 4.8$ & $a b$ & $9.2 \pm 0.6$ & $b c$ & $10.1 \pm 0.6$ & $\mathrm{~cd}$ & $95.3 \pm 0.6$ & a & $91.4 \pm 1.2$ & $a b$ \\
\hline
\end{tabular}

For each parameter, different letters indicate significant differences between data within the same column.

that the model explains maximum variation caused by the regression coefficient.

\section{Discussion}

Using a very simple apparatus with a wind speed of $1.8 \mathrm{~m} / \mathrm{s}$, approximately 40,000 eggs were dried in $20 \mathrm{~min}$ without any reduction in the percent hatch. When the size of the screen hole was increased from $6 \mathrm{~cm}$ to $9 \mathrm{~cm}$, approximately the same number of eggs was dried in 10 min (I. Khan, personal observation). Tubergen et al [11] also used a simple apparatus to dry eggs of An. stephensi Liston, and stored dried eggs at $4^{\circ} \mathrm{C}$. They reported an egg viability of $50 \%$ after five days in storage. In the present experiments more than $75 \%$ viability for up to eight days has been observed, and no significant reduction in larval survival was observed after the eggs were stored in bulk for eight days at $20^{\circ} \mathrm{C}$.
The present results on egg viability after storage at various temperatures are not consistent with those reported by Bailey et al. [13] for An. albimanus eggs, where a $90 \%$ hatch rate was reported after storage of up to 7 days at $10-16^{\circ} \mathrm{C}$. In this study, a $76 \%$ hatch after storage for up to 8 days at $20^{\circ} \mathrm{C}$ in bulk condition was recorded. A much lower hatch rate was observed after a storage duration of over 8 days at 10 or $15^{\circ} \mathrm{C}$, (Table 2). Nevertheless, the findings are consistent with Bailey et al. for An. albimanus and An. quadrimaculatus on the high rate of egg viability when stored in bulk condition. In the present study, a $75-80 \%$ hatch rate in the control and after storage periods of up to 8 days has been observed. The normal hatch rate of $A n$. arabiensis eggs is about $80 \%$. Thus, evidently $A n$. arabiensis eggs can be safely stored at $20^{\circ} \mathrm{C}$ for up to 6 days without any reduction in hatch rate, and for up to 9 days with no negative effects on the development and

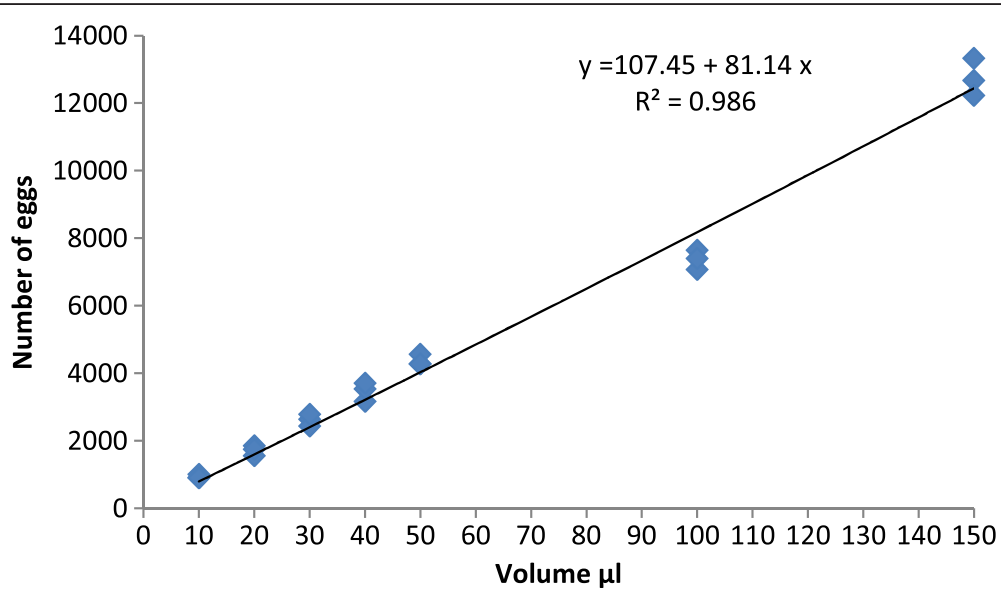

Figure 4 Volumetric estimation of dried eggs of An. arabiensis. 
survival of the larvae. As the hatch rate of eggs following 11 days of storage in bulk was quite low, other parameters were not further studied.

A temperature lower than $20^{\circ} \mathrm{C}$, permits storage for a few days but induces a decrease in the hatch rate with time; this suggests that a lower temperature has detrimental effects on An. arabiensis embryos. There are many studies on the influence of temperature at the early developmental stages of insects [17-22] and specifically those of mosquitoes including Anopheles gambiae [23], Anopheles albitarsis, Anopheles aquasalis [19], Aedes aegypti [24,25] and Culex spp. A strong influence of temperature on the embryonic development and hatchability of An. albitarsis and An. aquasalis has also been reported [26]. Microscopic observations on An. gambiae embryos showed that extreme low and high temperatures affected normal development [27]. This might be the case in the present study where a high rate of hatch and no significant hindrance in development was observed when eggs were stored in bulk at $20^{\circ} \mathrm{C}$.

An accurate and simple method to estimate the quantity of dried eggs has been developed, allowing for the quantification of several thousand eggs. In mass rearing conditions, larval development in a large 100 (l) x $60(\mathrm{w}) \times 3 \mathrm{~cm}(\mathrm{~d})$ rearing tray resulted in the production of more than 3500 pupae from $4000 \mathrm{~L} 1$ larvae [20]. Knowing that the natural hatch rate of the Dongola strain after drying and storage is about $70 \%, 5700$ dried eggs per tray are needed. With the equation established [volume of eggs $=$ (number of eggs 107.45)/81.14], the volume of eggs for $69 \mu \mathrm{l}$ can be estimated. A little spoon with a volume of $69 \mu \mathrm{l}$ could be created to allow for a rapid distribution of eggs into numerous trays from a stock of dried eggs collected from mass rearing cages.

\section{Conclusion}

Anopheles arabiensis eggs can be stored in bulk condition at $20^{\circ} \mathrm{C}$ for up to 6 days without any reduction in hatch rate and up to 9 days with no significant negative impact on larval development.

\section{Competing interests}

The authors declared that they have no competing interests.

\section{Authors' contributions}

The initial experimental set up was developed, executed and manuscript drafted by I. K. D. D., performed statistical analysis and helped in the development of the manuscript. S. M.S. helped in maintaining the laboratory colony, J.R.L.G., managed the overall experiment and critically reviewed the final draft of the manuscript. All authors approved the final version of the manuscript.

\section{Acknowledgements}

We are thankful for the full cooperation of scientists and staff working in the Mosquito Group of the Insect Pest Control Laboratories (IPCL) of the IAEA. This study was partially funded by the Pakistan Higher Education Commission (HEC) and the Pakistan Atomic Energy Commission (PAEC), and forms part of the postdoctoral report of the first author. We are grateful to both organizations for financial support.

\section{Author details}

'Nuclear Institute for Food and Agriculture, G.T. Road, Peshawar, Pakistan. ${ }^{2}$ Insect Pest Control Laboratory, Joint FAO/IAEA Division of Nuclear Techniques in Food and Agriculture, International Atomic Energy Agency, Vienna, Austria.

Received: 8 May 2013 Accepted: 10 September 2013

Published: 12 September 2013

\section{References}

1. Knipling EF: Possibilities of insect control or eradication through the use of sexually sterile males. J Econ Entomol 1955, 8:459-469.

2. Kaiser PE, Bailey DL, Lowe RE: Release strategy evaluation of sterile males of Anopheles albimanus with competitive mating. Mosq News 1981, 41:60-66.

3. Dame DA, Lowe RE, Williamson DL: Assessment of released sterile Anopheles albimanus and Glossina morsitans morsitans. In Cytogenetics and genetics of vectors. Edited by Pal R, Kitzmiller J, Kanda TA. Netherlands: Elsevier Biomedical; 1981:231-248.

4. Robinson A, Knols B, Voigt G, Hendrichs J: Conceptual framework and rationale. Malar J 2009, 8(Suppl 2):S1.

5. Khan I, Farid A, Zeb A: Development of inexpensive and globally available larval diet for rearing Anopheles stephensi (Diptera: Culicidae) mosquitoes. Parasit Vectors 2013, 6:90.

6. Damiens D, Benedict MQ, Wille M, Gilles JRL: An Inexpensive and Effective Larval Diet for Anopheles arabiensis (Diptera: Culicidae): Eat Like a Horse, a Bird, or a Fish? J Med Entomol 2012, 49:1001-1011.

7. Benedict M, Knols B, Bossin H, Howell P, Mialhe E, Caceres C, Robinson A: Colonisation and mass rearing: learning from others. Malar J 2009, 8(Suppl 2):S4.

8. Balestrino F, Benedict M, Gilles J: A new larval tray and rack system for improved mosquito mass rearing. J Med Entomol 2012, 49:595-605.

9. Balestrino F, Gilles JR, Soliban SM, Nirschl A, Benedict QE, Benedict MQ Mosquito mass rearing technology: a cold-water vortex device for continuous unattended separation of Anopheles arabiensis pupae from larvae. J Am Mosa Control Assoc 2011, 27:227-235.

10. Clements AN: The biology of mosquitoes. London: Chapman \& Hall; 1992.

11. Tubergen TA, Breaud TP, McConnell E: A technique for drying eggs of Anopheles stephensi and its effect on their viability after storage at $4^{\circ} \mathrm{C}$. Mosq News 1978, 38:583-585.

12. Dame DA, Lofgren CS, Ford HR, Boston MD, Baldwin KF, Jeffery GM: Release of chemosterilized males for the control of Anopheles albimanus in El Salvador II. Methods of rearing, sterilization, and distribution. Am J Trop Med Hyg 1974, 23:282-287.

13. Bailey DL, Thomas JA, Munroe WL, Dame DA: Viability of eggs of Anopheles albimanus and Anopheles quadrimaculatus when dried and stored at various temperatures. Mosq News 1979, 39:113-116.

14. Dame DA, Haile DG, Lofgren CS, Baily DL, Munroe WL: Improved rearing techniques for larval Anopheles albimanus: use of dried mosquito eggs and electric heating tapes. Mosq News 1978, 38:68-73.

15. Breeland SG, Jeffery GM, Lofgren CS, Weidhaas DE: Release of chemosterilized males for the control of Anopheles albimanus in El Salvador I. Characteristics of the test site and the natural population. Am J Trop Med Hyg 1974, 23:274-281.

16. Neter J, Kutner M, Nachtsheim C, Wasserman W: Applied linear statistical models. 4th edition. WCB: McGraw-Hill; 1996.

17. Howe RW: Temperature effects on embryonic development in insects. Annu Rev Entomol 2003, 12:15-42.

18. Huang J, Miller JR, Chen SC, Vulule J, Walker ED: Anopheles gambiae (Diptera : Culicidae) oviposition in response to agarose media and cultured bacterial volatiles. J Med Entomol 2005, 43:498-504.

19. Benedict MQ, Cockburn AF, Seawright JA: Heat-shock mortality and induced thermotolerance in larvae of the mosquito Anopheles albimanus. J Am Mosa Control Assoc 1991, 7:547-550.

20. Jang EB, Nagata JT, Chan HT, Laidlaw WG: Thermal death kinetics in eggs and larvae of Bactrocera latifrons (Diptera: Tephritidae) and comparative thermotolerance to three other Tephritid fruit fly species in Hawaii. J Econ Entomol 1999, 92:684-690.

21. Omkar, Pervez A: Temperature-dependent development and immature survival of an aphidophagous ladybeetle, Propylea dissecta (Mulsant). J Appl Entomol 2004, 128:510-514. 
22. Waddell BC, Jones VM, Petry RJ, Sales F, Paulaud D, Maindonald JH, Laidlaw WG: Thermal conditioning in Bactrocera tryoni eggs (Diptera: Tephritidae) following hot-water immersion. Postharvest Biol Tech 2000, 21:113-128.

23. Koenraadt CJM, Paaijmans KP, Githeko AK, Knols BGJ, Takken W: Egg hatching, larval movement and larval survival of the malaria vector Anopheles gambiae in desiccating habitats. Malar J 2003, 2:20.

24. Farnesi LC, Martins AJ, Valle D, Rezende GL: Embryonic development of Aedes aegypti (Diptera: Culicidae): influence of different constant temperatures. Mem Inst Oswaldo Cruz 2009, 104:124-126.

25. Trpis M, Haufe WO, Shemanchuk JA: Embryonic development of Aedes (O.) sticticus (Diptera: Culicidae) in relation to different constant temperatures. Can Entomol 1973, 105:43-50.

26. Carvalho SCG, Martins Junior AJ, Lima JBP, Valle D: Temperature influence on embryonic development of Anopheles albitarsis and Anopheles aquasalis. Mem Inst Oswaldo Cruz 2002, 97:1117-1120.

27. Impoinvil DE, Cardenas GA, Gihture Jl, Mbogo CM, Beier JC: Constant temperature and time period effects on Anopheles gambiae egg hatching. J Am Mosq Control Assoc 2007, 23:124-130.

doi:10.1186/1475-2875-12-318

Cite this article as: Khan et al.: Effects of drying eggs and egg storage on hatchability and development of Anopheles arabiensis. Malaria Journal 2013 12:318.

\section{Submit your next manuscript to BioMed Central and take full advantage of:}

- Convenient online submission

- Thorough peer review

- No space constraints or color figure charges

- Immediate publication on acceptance

- Inclusion in PubMed, CAS, Scopus and Google Scholar

- Research which is freely available for redistribution 